\title{
EVALUATION OF INSULIN- LIKE GROWTH FACTOR BINDING PROTEIN-1 IN DIAGNOSIS OF PRETERM PREMATURE RUPTURE OF FETAL MEMBRANES
}

\author{
By \\ Ahmed Salah Bakr, Mohamed Ali Mohamed, Adel Aly El-Boghdady and \\ Mohamed Sad El-Deen Radwan*
}

Departments of Obstetrics \& Gynecology and Clinical Pathology*, Faculty of Medicine, Al-Azhar University

Corresponding author: Ahmed Salah Bakr, E-mail: ahmedbaker1717@gmail.com

\begin{abstract}
Background: Premature rupture of membranes (PROM) is preterm (PPROM) when it occurs before 37 weeks gestation. It is a complication of $2 \%$ to $20 \%$ of all deliveries and is a known important contributor to maternal and perinatal morbidity and perinatal mortality.

Objective: To assess the accuracy of the uses of insulin-like growth factor binding protein-1 (IGFBP-1) in prediction of preterm premature rupture of membranes.

Patients and Methods: This comparative cross sectional study included 90 pregnant women between 28-36 weeks of gestation complaining of watery vaginal discharge, carried out at Sayed Galal hospital, Al-Azhar University between August, 2018 and August, 2020.

Results: This study showed no statistically significant differences regarding maternal age, parity and gestational age at recruitment.IGFBP-1 (Actim PROM test) was more sensitive and specific in diagnosing rupture of membranes than Nitrazine test. The sensitivity and the specificity of IGFBP-1 (Actim PROM test) in diagnosing PROM was $89.7 \%$ and $86.9 \%$ respectively as compared to Nitrazine test which was $75.9 \%$ and 82.0\%. The PPV and NPV of IGFBP-1 were $76.5 \%$ and $94.6 \%$ as compared to Nitrazinet test which were $66.7 \%$ and $87.7 \%$.
\end{abstract}

Conclusion: One step cervicovaginal IGFBP-1 (Actim PROM) dipstick was a rapid reliable, non-invasive, easy and accurate diagnostic test for PROM.

Keywords: Premature rupture of membranes, Adrenocorticotropic hormone, Biophysical profile.

\section{INTRODUCTION}

Premature rupture of membranes (PROM) is rupture of the fetal membranes before the onset of labor, and approximately $8-10 \%$ of term pregnancies will experience PROM prior to the onset of uterine activity (ACOG, 2017). While rupture of fetal membranes before 37 weeks gestation is defined as preterm premature rupture of membranes (PPROM) (Medina and Hill, 2016).

P-PROM is usually associated with significant perinatal and maternal infectious morbidities. During the management of patients with P-PROM, the clinician weighs the risk of prolonging gestation against the risks of serious fetal and maternal consequences (Mercer et al., 2015). 
Failure to identify patients with PPROM can result in failure to implement standard measures and conversely an incorrect diagnosis leads to inappropriate interventions (such as hospitalization or induction of labor). Therefore, the diagnosis of P-PROM is of critical importance to avoid serious fetal or maternal consequences (Mercer et al., 2015).

Accurate diagnosis of P-PROM remains a frequent clinical problem in obstetrics. Unfortunately, a non-invasive standard diagnostic test is not available at this time. The diagnosis of P-PROM is usually based on the patient's history, identification of gross pooling of amniotic fluids from the cervical canal during sterile speculum examination, and the Nitrazine test. Nitrazine evaluation has been associated with false positive results in $17.4 \%$ and false negative results in 12.9\% (Abdelazim and Makhlouf, 2015).

The absence of a non- invasive gold standard for the diagnosis of rupture of fetal membranes resulted in the appearance of several tests based on alternative biochemical markers. These biochemical markers include vaginal prolactin, alpha- feto - protein (AFP), fetal fibronectin and insulin - like growth factor binding protein-1 (IGFBP-1). However, prolactin and AFP were not useful markers for PROM because of the overlap in concentrations between women with and without ruptured membranes (Buyukbayrak et al., 2016).

Human chorionic gonadotrophin (hCG) has been evaluated as a marker for PROM and, unfortunately, the quantitative evaluation of hCG as a marker for PROM is costly and time consuming (Kim et al., 2015).

Several studies suggested that the detection of IGBP-1 in the vaginal fluid will provide qualitative results that exceed the current diagnostic methods in sensitivity and specificity (Erdemoghlu and Mungan, 2018).

The aim of the present work was to assess the accuracy of the uses of IGFBP1 in prediction of preterm premature rupture of membranes.

\section{PATIENTS AND METHODS}

This was comparative cross-sectional study that carried out at Sayed Galal Hospital, Obstetrics and Gynecology Department, Faculty of Medicine, AlAzhar University from August 2018 to August 2020.

Sample size: The study included 90 pregnant women between 28-36 weeks of gestation complaining of watery vaginal discharge. Sample size was calculated using epiInfo ${ }^{\circledR}$ version 6.0 , setting the type-1 error $(\alpha)$ at 0.05 and the power (1$\alpha)$ at 0.80 (Abdelazim and Makhlouf, 2015).

Inclusion Criteria: Gestational age between 28-36 weeks was calculated from the first day of last menstrual period or by ultrasonographic examination before 14 weeks, Age 20-40 years old, single intrauterine pregnancy, and history of watery vaginal leakage.

Exclusion Criteria: Vaginal bleeding either spontaneous or due to speculum examination. History of infection, e.g. vaginitis, cervicitis, vaginal washing with antiseptics, occurrence of vaginal intercourse during previous 48 hours, fetal 
distress, multiple pregnancy, chorioamionitis: diagnosed by clinical examination and investigations as CRP, $\mathrm{CBC}$, placenta praevia, patients with established labor pains.

Informed written consent was taking from all patients and the study was approved by local ethical committee.

\section{All women included in the study were subjected to the following:}

Detailed history taking, general and abdominal examination and sterile Cusco speculum examination.

Samples collection: Patients were examined in a dorsal lithotomy position with good illumination using sterile speculum (without antiseptics). Two sterile swabs were used to collect the samples from the posterior vaginal fornix after insertion of the speculum (the swabs should not touch the vaginal wall during insertion or during removal).

Nitrazine test: The first sterile swab impregnated with Nitrazine yellow dye was inserted in the posterior vaginal fornix for 15 seconds, and the color of the swab was interpreted after removal of the swab from the vagina. The blue color was considered as positive (PROM) and other colors was considered as negative (no PROM).

\section{IGFBP-1 (Actim PROM Test):}

According to the manufacturer's instructions, the second polyester swab provided with the kit was inserted into the vagina for 10-15 seconds, then rinsed in the provided specimen extraction solution or buffer for 10 seconds, then removed from the solution and disposed. The yellow area of the dipstick will dipped into the specimen extraction solution, removed when the liquid reached the result window and the result was interpreted as soon as it was visible. If only one blue line was visible, the test result was negative (no PROM). If two blue lines were visible, the test result was positive (PROM), and if no lines were visible the test was not functioning properly, or it was an invalid test. One blue line on dipstick confirms that the test has been performed correctly, and there was no IGFBP-1 in the vaginal fluid (no PROM). Two blue lines on the dipstick indicated that the sample contains IGFBP1 (above $28 \mu \mathrm{g} / \mathrm{l}$ ), and the test was positive for PROM.

\section{Statistical Methods:}

The collected data were coded, tabulated, and statistically analyzed using IBM SPSS statistics (Statistical package for the Social Sciences) software version 22.0 IBM Corp., Chicago, USA, 2013. Descriptive statistics were done for quantitative data as mean \pm SD (standard deviation), minimum \& maximum of the range as well as $95 \%$ confidence interval (CI) for quantitative parametric data, while it was done for qualitative data as number and percentage as well as 95\% confidence interval (CI). Inferential analyses were done for quantitative variables using independent t-test in cases of two independent groups with parametric data. In qualitative data, inferential analyses for independent variables were done using chi square test for difference between proportions and McNemar test for agreement between paired categorical data.

Diagnostic charateristics were calculated as follows: Sensitivity, specificity, positive predictive value, 
negative predictive value, and diagnostic taken at $\mathrm{P}$ value $<0.05$ was significant.

accuracy. The level of significance was

\section{RESULTS}

As regards descriptive data of the patients characteristics: Mean \pm SD of age was found $29.5 \pm 3.6$ as regards parity $32.2 \mathrm{~m}$ and of the patients were PG, $67.8 \%$ were multipara, meant SD of BMI was $29.1 \pm 1.6$, and meant SD of gestational age was $32.0 \pm 1.7$ (Table 1).

Table (1): Age, BMI, GA and parity among the studied cases

\begin{tabular}{|c|c|c|c|}
\hline \multicolumn{2}{|c|}{ Variables } & Mean \pm SD & Range \\
\hline \multicolumn{2}{|c|}{ Age (Years) } & $29.5 \pm 3.6$ & $20.0-39.0$ \\
\hline \multicolumn{2}{|c|}{ BMI(kg/m2) } & $29.1 \pm 1.6$ & $24.6-33.3$ \\
\hline \multicolumn{2}{|c|}{ GA (weeks) } & $32.0 \pm 1.7$ & $27.4-37.0$ \\
\hline \multicolumn{2}{|c|}{} & $\mathrm{N}$ & $\%$ \\
\hline \multirow{2}{*}{ Parity } & Primiparous & 29 & 32.2 \\
\cline { 3 - 5 } & Multiparous & 61 & 67.8 \\
\hline
\end{tabular}

Total $=90$

Less than one-third of cases had PROM by Cusco speculum (Table 2).

Table (2): PROM by sterile cusco examination (golden standard test), Nitrazine test and IGFBP-1 test among the studied cases

\begin{tabular}{|c|c|c|}
\hline Method & PPROM (N) & \% \\
\hline Golden standard test & $\mathbf{2 9}$ & $\mathbf{3 2 . 2}$ \\
\hline Nitrazine test & $\mathbf{3 3}$ & $\mathbf{3 6 . 7}$ \\
\hline IGFBP-1 test & $\mathbf{3 4}$ & $\mathbf{3 7 . 8}$ \\
\hline
\end{tabular}

Total $=90$

No significant difference between PROM and non- PROM (by examination)

regarding age, BMI, GA and parity (Table 3).

Table (3): Comparison between PROM and non- PROM (by golden test) regarding age, BMI, GA and parity

\begin{tabular}{|c|c|c|c|c|}
\hline \multicolumn{2}{|c|}{ Variables } & $\begin{array}{l}\text { PROM } \\
(\mathrm{N}=29)\end{array}$ & $\begin{array}{c}\text { Non PPROM } \\
(\mathbf{N}=61)\end{array}$ & $P$ value \\
\hline \multicolumn{2}{|c|}{ Age (Years) } & $30.2 \pm 2.9$ & $29.1 \pm 3.8$ & $>0.05$ \\
\hline \multicolumn{2}{|c|}{ BMI(kg/m2) } & $29.0 \pm 1.6$ & $29.2 \pm 1.7$ & $>0.05$ \\
\hline \multicolumn{2}{|c|}{ GA (weeks) } & $32.0 \pm 1.7$ & $32.2 \pm 1.7$ & $>0.05$ \\
\hline \multirow{2}{*}{ Parity } & Primiparous & $8(27.6 \%)$ & $21(34.4 \%)$ & \multirow{2}{*}{$>0.05$} \\
\hline & Multiparous & $21(72.4 \%)$ & $40(65.6 \%)$ & \\
\hline
\end{tabular}

^Independent t-test, \# Chi square test

There were agreements between sterile cusco examination (golden standard test), nitrazine test. and igfbp-1 test (Table 4). 
Table (4): Agreement between (golden test), nitrazine test, Cusco speculum examination (golden standard test) and IGFBP-1test

\begin{tabular}{|c|c|c|c|c|}
\hline \multirow{2}{*}{ Tests } & Cusco Speculum & $\begin{array}{c}\text { PPROM } \\
(\mathbf{2 9})\end{array}$ & $\begin{array}{c}\text { Non-PPROM } \\
(\mathbf{6 1})\end{array}$ & \multirow{2}{*}{ p value } \\
\hline $\begin{array}{c}\text { Nitrazine } \\
\text { test }\end{array}$ & PROM (33) & $22(24.4 \%)^{\mathrm{TP}}$ & $11(12.2 \%)^{\mathrm{FP}}$ & \multirow{2}{*}{$>\mathbf{0 . 0 5}$} \\
\cline { 2 - 4 } & Non- PROM (57) & $2(7.8 \%)^{\mathrm{FN}}$ & $50(55.6 \%)^{\mathrm{TN}}$ & \\
\hline \multirow{2}{*}{ IGFBP-1 } & PROM (34) & $22(28.9 \%)^{\mathrm{TP}}$ & $8(8.9 \%)^{\mathrm{FP}}$ & \multirow{2}{*}{$>\mathbf{0 . 0 5}$} \\
\cline { 2 - 4 } & Non- PROM (57) & $3(3.3 \%)^{\mathrm{FN}}$ & $53(58.9 \%)^{\mathrm{TN}}$ & \multirow{2}{*}{} \\
\hline
\end{tabular}

Percentages are taken from total $=90, \wedge \mathrm{McNemar}$ test

TP: Tru positive, TN: True negative, FP: false positive, FN: False negative.

The diagnostic characteristic in the diagnosis of PROM (Cusco speculum examination was a golden test) was higher in IGFBP-1 test than nitazine test. As Sensitivity of IGFBP-1 (Actiom PROM test) was found $89.7 \%$ in comparision to
Nitrazine test which was $75.9 \%$. As regards specificity of IGFBP-1 (Actiom PROM test), it was found $86.9 \%$ in comparision to Nitrazine test which was $82 \%$ (Table 5).

Table (5): Diagnostic characteristics of nitrazine and IGFBP-1 test in diagnosis of PPROM (Cusco speculum examination was a golden test)

\begin{tabular}{|c|c|c|c|c|}
\hline \multirow{2}{*}{ Tests } & \multicolumn{2}{|c|}{ Nitrazine } & \multicolumn{2}{c|}{ IGFBP-1 } \\
\cline { 2 - 5 } Characteristics & Value & $\mathbf{9 5 \%}$ CI & Value & 95\%CI \\
\hline Sensitivity & \multirow{2}{*}{$75.9 \%$} & $\begin{array}{c}72.1 \%- \\
763 \%\end{array}$ & $89.7 \%$ & $\begin{array}{c}87.8 \%- \\
90.0 \%\end{array}$ \\
\hline Specificity & \multirow{2}{*}{$82.0 \%$} & $\begin{array}{c}79.0 \%- \\
82.4 \%\end{array}$ & \multirow{2}{*}{$86.9 \%$} & $\begin{array}{c}84.5 \%- \\
87.2 \%\end{array}$ \\
\hline Positive predicitive value \\
(PPV)
\end{tabular}

CI: confidence interval

\section{DISCUSSION}

Accurate diagnosis of PROM remains a frequent clinical problem in obstetrics. Unfortunately, a non-invasive standard diagnostic test is not available at this time. The diagnosis of PROM is usually based on the patient's history, identification of gross pooling of amniotic fluids from the cervical canal during sterile speculum examination, after microscopic examination and the Nitrazine test (Abdelazim and Makhlouf, 2015).
Correct diagnosis of PROM is of great importance because failure of diagnosis can lead to unwanted obstetric complications such as chorioamnionitis, preterm birth; on the other hand over diagnosis can lead to unnecessary interventions like hospitalization (Kafali and Oksuzler, 2016).

The approach to the diagnosis of rupture membrane is clinical, with over $90 \%$ of cases being confirmed based on the presence of a suspicious history or 
ultrasonographic finding followed by documentation of fluid passing from the cervix or the presence of a nitrazine/ positive vaginal pool of fluid. Various methods were used to diagnose (Mercer, 2020).

PROM such as nitrazine and ferning test, but has low sensitivity and specificity, or injection of intra- amniotic dye, although are very reliable test but are invasive with serious complications (Abdelazim and Makhlouf, 2015).

The absence of a non- invasive gold standard test for the diagnosis of rupture membrane has led to the search for an alternative biochemical marker, vaginal prolactin (PRL), $\alpha$ - Fetoprotein (A-FP), fetal fibronectin, Growth hormone $(\mathrm{GH})$, insulin growth factor binding protein-1 (IGFBP-1), interlukin-6 (II-6), human placental lactogen (HPL), diamion- oxidas or their combinations. All these tests have advantages as well as drawback (Abdelazim \& Makhlouf, 2015 and Hitti et al., 2016).

During pregnancy, the insulin- like growth factor binding protein-1 (IGFBP1) is produced in decidua and exists in high concentration in $\mathrm{AF}$ and maternal serum (Martina et al., 2019).

Insulin- like growth factor binding proteins (IGFBPs) has high affinity to insulin- like growth factors (IGFs) and antagonizes the binding of IGFs to their receptors. Several studies indicated that MMPs (Matrix metalloproteinases) act as IGFBP proteases and proteolytic cleavage of IGFBPs by specific MMPs has been reported.

This study was cross sectional study to determine if measurement of levels insulin growth factor binding protein-1 (IGFBP1) (Actim- PROM) in washed vaginal fluid were useful for the diagnosis of premature rupture of membranes.

This study showed no statistically significant difference as regards maternal age, BMI or parity, and this agreed with the study done by (Abdelazem and Makhlouf, 2015). Shahin and Raslan (2017) reported lower gestational age at delivery among case group.

This study showed no statistically significant difference as regard parity. This was in agreement with the results obtained by Anai et al. (2012) and Kim et al. (2015).

In this study, the IGFBP-1 (ActimPROM test) was more sensitive and specific in diagnosing rupture of membranes than Nitrozatin test. The sensitivity and the specificity of IGFBP-1 (Actim PROM test) in diagnosing PPROM was $89.7 \%$ and $86.9 \%$ and $82.0 \%$. The PPV and NPV of IGFBP-1 were $76.5 \%$ and $94.6 \%$ as compared to Nitrazine test which were $66.7 \%$ and $87.7 \%$.

In this study, the nitrazine test gave false negative resulted in $7.8 \%$ of cases of definite PPROM and false positive result in $12.2 \%$ cases without PPROM. This failure to identify patients with PROM can result in failure to implement standard measures, such as hospitalization or antibiotics therapy. The clinical usefulness of IGFBP-1 dipstick test in the detection of ROM was evaluated by (Rutanen et al. (2015).

The performance of two rapid tests for the diagnosis of PROM based on the detection of IGFBP-1 and placental alpha- 
microglobulin-1 (PAMG-1) in cervicovaginal secretions were compared by Marcellin et al. (2014) who found that the AmniSure (PAMG-1) in cervicovaginal secretions were compared. They found that the AmniSure (PAMG-1) test was $95 \%$ sensitive, $94.8 \%$ specific, with $95 \%$ PPV and $94.8 \%$ NPV in diagnosing PROM, while the Actim PROM (IGFBP-1) test was $97.5 \%$ sensitive, 97.4\% specific, with 97.5\%PPV and $97.4 \%$ NPV in diagnosing PROM. Marcellin et al. concluded that both AmniSure (PAMG-1) and Actim PROM (IGFBP-1) tests have similar performance to diagnose premature rupture of membranes (Marcellin et al., 2014).

Also, the diagnostic efficacy of PAMG-1 and IGFBP-1 test in PROM were evaluated by Albayrak et al. (2016), and they concluded that both rapid bedside strip tests may be used in clinical practice with similar efficacy in diagnosing PROM, particularly as a backup when diagnosis is still in doubt following a combination of conventional I diagnostic methods.

The value of IGFBP-1 and other tests for the diagnosis of PROM were evaluated by Martinez de Tejada et al. (2016) who found that the IGFBP-1 was $86 \%$ sensitive, $74 \%$ specific, with $73 \%$ PPV and $87 \% \mathrm{NPV}$ in diagnosing ROM, and they concluded that the dipstick test of IGFBP-1 is a sensitive bedside test for detection of PROM.

\section{CONCLUSION}

One step cervicovaginal IGFBP-1 (Actim prom) dipstick was a rapid reliable, non-invasive, easy and accurate diagnostic test for PPROM. Another advantage of this method was that only contamination of specimen with blood could affect the true results of these methods, while Nitrazine tests could be affected by many factors. This dipstick was easily and rapidly available in all settings without any need to complex laboratory equipment.

\section{REFERENCES}

1. Abdelazim IA and Makhlouf HH (2015): placental alpha macroglobulin-1 (AmniSure test) for detection of premature rupture of fetal membranes. Arch Gynecol Obstet., 285:985989.

2. American College of Obstetrics and Gynecology: ACOG (2017): Clinical management guidelines for obstetrician gynecologists (ACOG Practice Bulletin No. 80: premature rupture of membranes). Obstet Gynecol., 109:1007-19.

3. Anai $T$, Tanaka $Y$, Hirota $Y$ and Miyakawa I. (2012): Vginal fluid HCG level for detecting PROM. Obstet Gynecol., 89:261-4.

4. Buyukbayrak EE, Turan C,Unal O, Dansuk $R$ and Cengizoglu B (2016): Diagnostic power of the vaginal - washing fluid prolactin assay as an alternative method for the diagnosis of premature rupture of membrances. J Matern Fetal Neonatal Medicine, 15: 120-5.

5. Erdemoghlu $E$ and Mungan $T$ (2018): Significance of detecting insulin- like growth factor bindingprotein-1 in cervicovaginal secretions: comparison with nitrazine test and amniotic fluid volume assessment. Acta Obstet Gynecol Rprod Boil., 107:37-40.

6. Hitti J, Lapidus JA, Lu X, Reddy AP, Jacob TH and Dasari S. (2016): Noninvasive diagnosis of intra amniotic infection: proteomic biomarker in vaginal fluid American J of Obstet \& Gynecol., 203: 1-8.

7. Kafali $\mathbf{H}$ and Oksuzler $C$ (2016): Vaginal fluid urea and creatinine in diagnosis of premature rupture of membranes. Archives of gynecology and obstetrics, 275(3), 157-160.

8. Kim YH, Park YW, Kwon HS, Kwn JY and Kim BJ (2015): Vaginal fluid beta 
human chorionic gonadotropin in level in the diagnosis of premature rupture of membranes. Acta Obstet Gynecol Scand., 84:802-5.

9. Marcellin L, Anselem O, Guibourdenche J, De la Calle A, Deput-Rampon C, Cabrol D and Tsatsaris V (2014): Comparison of two bedside tests performed on cervicovaginal fluid to diagnose premature rupture of membranes. Journal De Gynecologie, Obstetrique et Biologie de la Reproduction, 40(7):651-56.

10. Martina NA, Kim E, Chitkara U, Wathen NC, Chard T and Giudice LC (2019): Gestational age-dependent expression of insulin-like growth factor-binding protein-1 (IGFBP-1) phosphoisoforms in human extraembryonic cavities, maternal serum, and decidua suggests decidua as the primary source of IGFBP-1 in these fluids during early pregnancy. The Journal of Clinical Endocrinology \& Metabolism, 82(6): 18941898.

11. Martinez de Tejada B, Boulvain M, Dumps P, Bischof P, Meisser A and Irion O (2016): Can we improve the diagnosis of rupture of membranes? The value of insulin-like growth factor binding protein-1. BJOG: An International Journal of Obstetrics \& Gynaecology, 113(9):1096-9.
12. Medina TM and Hill DA (2016): Preterm premature rupture of membranes: diagnosis and management. American Family Physician, 73(4): 659-664.

13. Mercer BM, Goldenberg RL and Meis PJ. (2015): The NICHD Maternal- Fetal Medicine Units Network, authors. The preterm predicition Study: Prediction of preterm premature rupture of membranes through clinical findings and ancillary testing. Am J Obstet Gynecol., 183:738-45.

14. Mercer, B. M. (2020): Premature rupture of the membranes. Protocols for High-Risk Pregnancies: An Evidence-Based Approach, 461-474.

15. Rutanen EM, Kärkkäinen TH, Lehtovirta J, Uotila JT, Hinkula MK and Hartikainen AL (2015): Evaluation of a rapid strip test for insulin-like growth factor binding protein-1 in the diagnosis of ruptured fetal membranes. Clinica Chimica Acta, 253(1-2):91-101.

16. Shahin $M$ and Raslan $H$ (2017): Comparative study of three amniotic fluid markers in premature rupture of membranes: prolactin, beta subunit of human chorionic gonadotropin, and alphafetoprotein. Gynecol Obstet Invest, 63:195-9. 


\section{تقييم البروتين -1 المرتبط بعامل النمو الثبيه بالانسولين في تشخيص التمزق المبكر للأغثية المحيطة بالجنين}

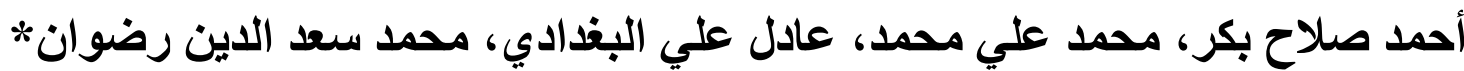

قسمي التوليد وأمراض النساء والباتولوجيا الإكلينيكية*،، كلية الطب، جامعة الأزهر

\section{E-mail: ahmedbaker1717@gmail.com}

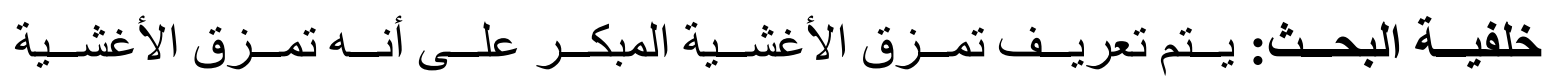

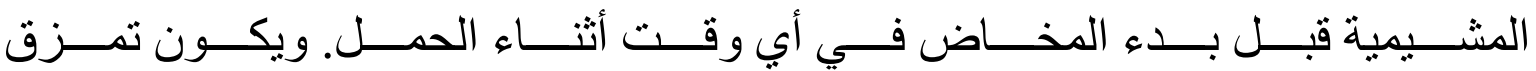

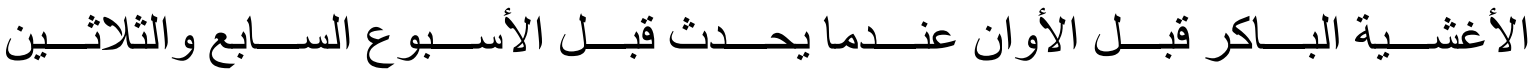

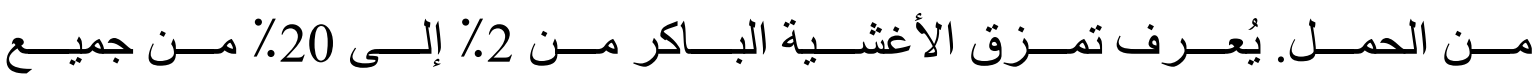

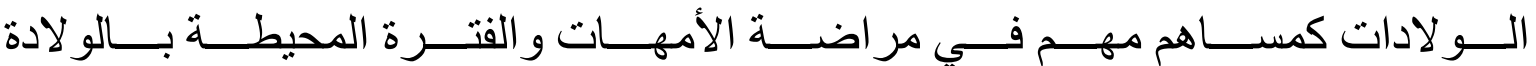
ووفيات الفترة المحيطة بالو لادة.

الهــدف مــن البحــث: التحقـتق مــن دقــة اســتخدام البــروتين-1 المتــربط بعامــل النــــو الثـــيه بالانســولين (إختبـــار أكتــيم بـروم) فــي التنبــوء بــالتمزق المبكـر لمأغشية المحيطة بالجنين.

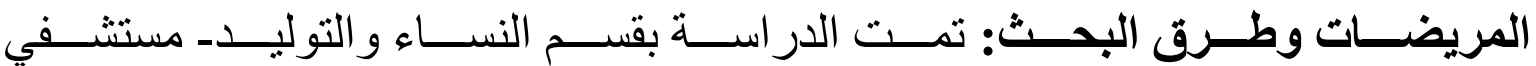

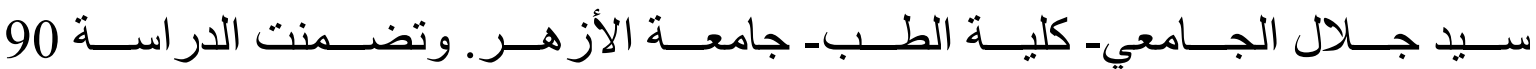

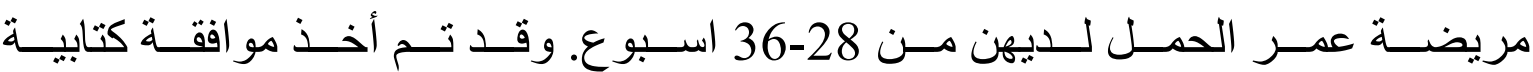

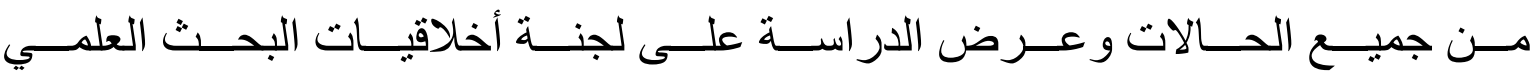
للتصديق عليها.

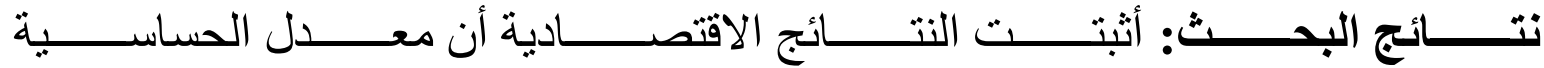

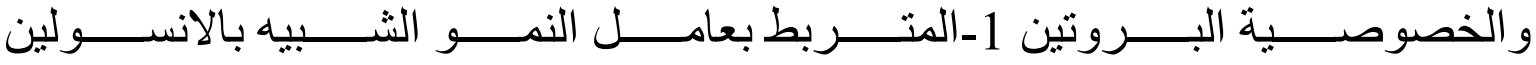

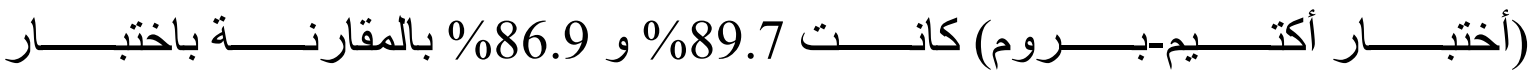

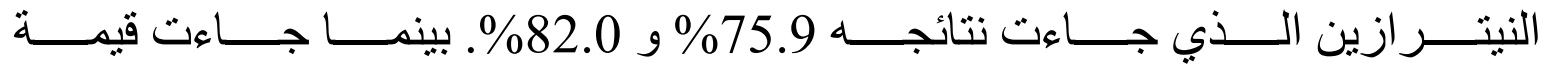




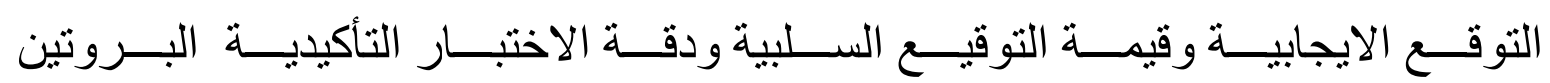

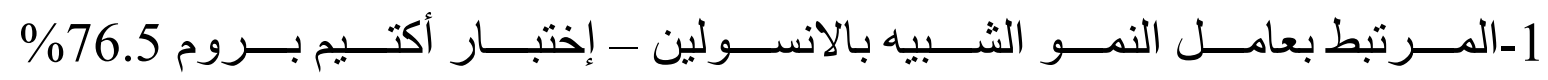
و 94.6\%. بينما جاءت نتائج إختبار النيترازين 66.7\% و بو \% \% \%

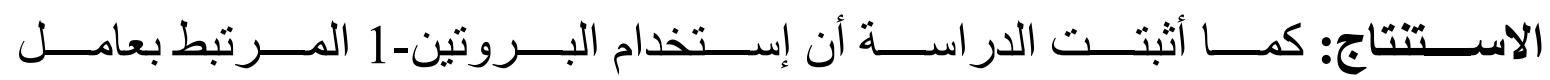

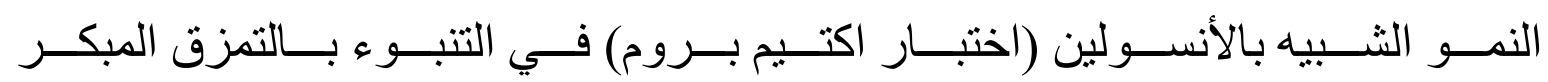

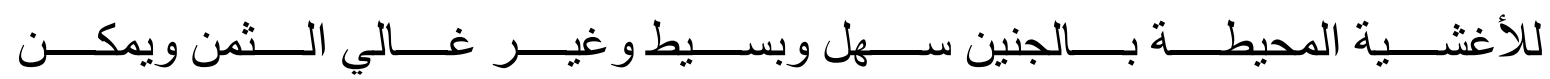
استخدامه في غرفة الاستقبال وهو أدق من إختيار النيترازين.

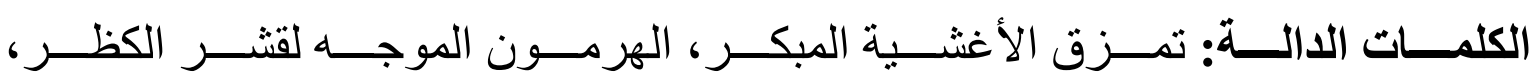
الملف الفيزيائي الحيوي. 